Check for updates

Cite this: RSC Adv., 2017, 7, 45714

Received 24th August 2017

Accepted 13th September 2017

DOI: $10.1039 / c 7 r a 09362 d$

rsc.li/rsc-advances

\section{Ring-locking strategy facilitating determination of absolute optical purity of 2-amino-1-butanol by reverse-phase high-performance liquid chromatography $\dagger$}

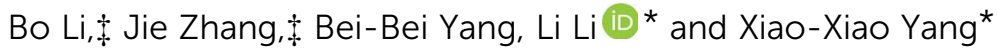

A concise and efficient reverse-phase high-performance liquid chromatography (RPLC) method has been established for absolute optical purity assay of 2-amino-1-butanol, which is an important synthetic intermediate of various drugs. Its enantiomers were derivatized with methyl (5-fluoro-2,4-dinitrophenyl)-(S)-prolinate, which could be regarded as a structural variant of Marfey's reagent. The resultant diastereomers were further cyclized using bis(trichloromethyl)carbonate to form oxazolidin-2-one ring, leading to a distinct difference in their electronic circular dichroism (ECD) spectra. Time-dependent density functional theory (TDDFT) was then applied to simulate theoretical ECD spectra for unambiguous absolute configuration assignment of cyclized products without putative samples. Both pairs of diastereomers could be separated on a reverse-phase C18 column using a mobile phase of methanol or acetonitrile and water with UV detection at $336 \mathrm{~nm}$. The tandem reactions could be integrated into onepot synthesis with high yield. Thus, exact absolute optical purity of 2-amino-1-butanol could be directly determined by monitoring the peak ratios of these diastereomers. This method is well worth extending to the absolute optical purity assessment of other chiral amino alcohols.
\end{abstract}

\section{Introduction}

Amino alcohols are important structural elements that are prevalently stemming from natural products. With the continuous concern about exploring chiral molecules, enantiopure amino alcohols are drawing increasing attention in recent years. ${ }^{1}$ Their potentials were excavated to synthesize biologically active compounds or building blocks for catalysts and auxiliaries in asymmetric synthesis. ${ }^{2}$ Enantiomerically pure amino alcohols have also emerged as pivotal intermediates in medicinal chemistry (Fig. 1). ${ }^{3}$

The most representative and immediate instance is the application of 2-amino-1-butanol (1, Fig. 1) to synthesize ethambutol (EMB), one of the front-line drugs against tuberculosis. $^{4}(S, S)$-EMB is the most effective agent against almost all the strains of Mycobacterium sps., causing an enhancement in activity of up to 200 -fold than $(R, R)$-enantiomer and mesoisomer. ${ }^{5}$ Moreover, it is reported that optical impurity of $(R, R)$ EMB could lead to serious visual impairment, which is the main

Beijing Key Laboratory of Active Substances Discovery and Druggability Evaluation, Institute of Materia Medica, Chinese Academy of Medical Sciences, Peking Union Medical College, Beijing 100050, China. E-mail: annaleelin@imm.ac.cn; Fax: +8610-63165247; Tel: +86-10-63165247; +86-10-63165251

$\dagger$ Electronic supplementary information (ESI) available: NMR, ESI-HRMS and computation data for $\mathbf{3}, \mathbf{4 a} / \mathbf{4 b}, \mathbf{5 a} / \mathbf{5 b}$. See DOI: $10.1039 / \mathrm{c} 7 \mathrm{ra09362d}$

\$ These authors contributed equally. side-effect in the clinic application of EMB. ${ }^{6}$ The classical and widespread methods to synthesize EMB mainly involved reacting 1,2-dihaloethane with $(S)-$ 1. $^{7}$ Accordingly, it is apparent that the enantiopurity of $\mathbf{1}$ dominates the optical purity of EMB. For the sake of gaining perfect antimycobacterial activity of EMB, the optical purity of $(S, S)$-configuration must be impeccable. Moreover, sustained efforts are carried out to explore derivatives of chiral 1 for more powerful antimycobacterial activity, with $R$ isomer being more active than $S$ isomer in some cases. ${ }^{\mathbf{8}}$ Therefore, taking the above-mentioned reasons into account, it is imperative and significant to establish an efficient and concise method to determine the absolute optical purity of chiral 1.

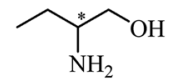

$(R)-$ or $(S)-1$<smiles>CC[C@H](CO)NCCN[C@H](CC)CO</smiles>

Ethambutol (EMB)

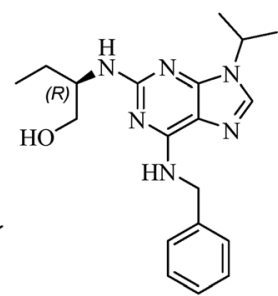

Roscovitine<smiles>CC[C@H](CO)NC(=O)C1C=C2c3cccc4[nH]cc(c34)CC2(C)N(C)C1</smiles>

Methylergonovine
Fig. 1 Chemical structures of 1 and drugs containing chiral 2-amino1-butanol moiety. 
Compound 1 is a highly polar molecule with low molecular weight and lack of sufficient UV chromophores. Conventional chromatographic analysis methods such as normal-phase highperformance liquid chromatography or gas-chromatography (GC) could only be utilized indirectly for its optical purity detection after derivatization using chiral stationary phase. ${ }^{9}$ There exists a few relevant reports of solutions to this thorny problem, such as use of 1,1'-bi-2-naphthol derivatives by virtue of NMR to determine their enantiomeric excesses (ee's), which showed up inevitable flaws in its accuracy and sensitivity. ${ }^{\mathbf{1 0}}$ Tremendous efforts have also been made to seek for novel chirality sensing of amino alcohols using stereodynamic or fluorescence probes. ${ }^{\mathbf{1 1}}$ Nevertheless, taking the advantages of accuracy and feasibility into consideration, RPLC could be a favourable choice for the rapid ee routine assessment in a laboratory.

It is widely shared that besides single-crystal X-ray diffraction, chiroptical spectroscopy including electronic circular dichroism (ECD) spectroscopy is an alternative way to establish absolute configurations of chiral molecules. In recent years, comparison of experimental ECD spectra with theoretical ECD curve obtained using quantum-chemical calculation and timedependent density functional theory (TDDFT) has been widely applied in the absolute configuration assignments of chiral drugs and natural products. ${ }^{\mathbf{1 2}}$

Marfey's reagent is regarded as the most successful derivatizing reagent for indirect resolution of chiral amino acids and amines on the standard reverse-phase column. ${ }^{13}$ It could also be used to determine the content of monoethanolamine in drug substance. ${ }^{\mathbf{1 4}}$ The characteristics and applications of Marfey's reagent have been fully reviewed by Bhushan. ${ }^{15}$ However, to the best of our knowledge, there has been no report on ECD spectra of these diastereomeric derivatives and absolute configuration assignments without putative samples.

In this study, we describe a simple and efficient approach to determine absolute configuration and enantiomeric composition of 1 using RPLC without putative samples. This method is based on forming the corresponding epimeric derivatives upon reaction of $\mathbf{1}$ with methyl (5-fluoro-2,4-dinitrophenyl)-(S)- prolinate, which could be regarded as a structural variant of Marfey's reagent. Their optical purity and absolute configuration verification were achieved by RPLC and ECD spectra analysis adopting a ring-locking strategy, respectively. This methodology could competently determine the enantiopurity of chiral 1 as expected.

\section{Results and discussion}

\section{Derivatization route}

Synthetic route of diastereomers is depicted in Scheme 1. First, we used methyl $(S)$-prolinate as nucleophile reagent to quantitatively substitute one fluorine atom of 2 . In this step, due to the strong electron-withdrawing effect of two nitro groups, nucleophilic aromatic substitution could readily take place to afford compound 3 with excellent yield and purity. The remaining fluorine atom of $\mathbf{3}$ was substituted by $(S) /(R)-\mathbf{1}$ at a refluxing temperature in THF to form diastereomers $\mathbf{4 a}$ or $\mathbf{4 b}$.

With compounds $\mathbf{4 a}$ and $\mathbf{4 b}$ in hand, we tried to assign their absolute configurations by ECD spectroscopy. However, their ECD spectra were assumed to be fairly similar as shown in Fig. 2. It is due to the fact that the dominant chiral factor disturbing the aromatic chromophore was the chiral carbon atom on the pyrrolidine ring, rather than that on the flexible alkyl chain. Accordingly, a ring-locking strategy was proposed to tether amino and hydroxyl groups with a carbonyl group, which could lock the conformation of flexible alkyl chain near the chiral centre. This was achieved by adopting bis(trichloromethyl)carbonate as acylation reagent to construct fivemembered heterocyclic compounds $\mathbf{5 a}$ and $\mathbf{5 b}$.

\section{Experimental UV-vis absorption and ECD spectra}

Experimental UV-vis absorption and ECD spectra of 3, 4a/4b and $\mathbf{5 a} / \mathbf{5 b}$ in methanol are demonstrated in Fig. 2. Substitution of a fluorine atom of $\mathbf{3}$ by $(S) /(R)-\mathbf{1}$ led to the transformation of the strong absorption at $348.0 \mathrm{~nm}$ into two peaks, with one red shifting up to $50 \mathrm{~nm}$ (from 348 to $402 \mathrm{~nm}$ ) and the other blue shifting to $335.5 \mathrm{~nm}$. Moreover, the absorption intensity also
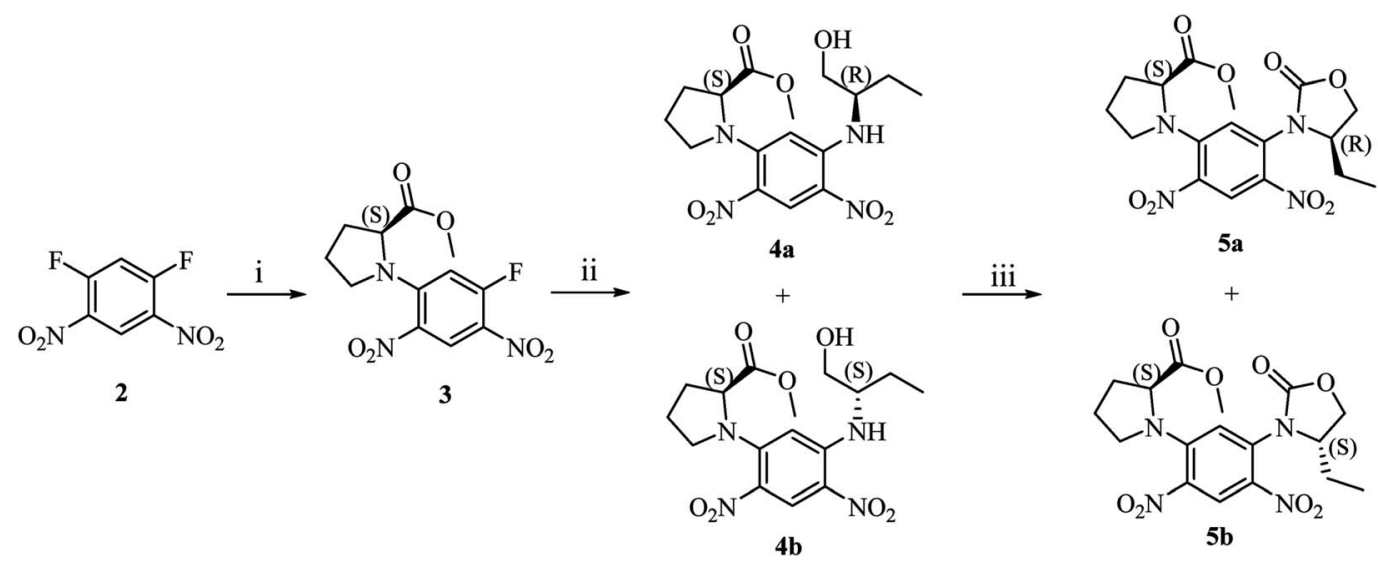

Scheme 1 (i). Methyl (S)-prolinate hydrochloride, DIPEA, THF, r.t., 5 h; (ii). (S)/(R)-1, DIPEA, THF, refluxing, 2 h; (iii). bis(trichloromethyl) carbonate, DIPEA, dichloromethane, r.t., $1 \mathrm{~h}$. 


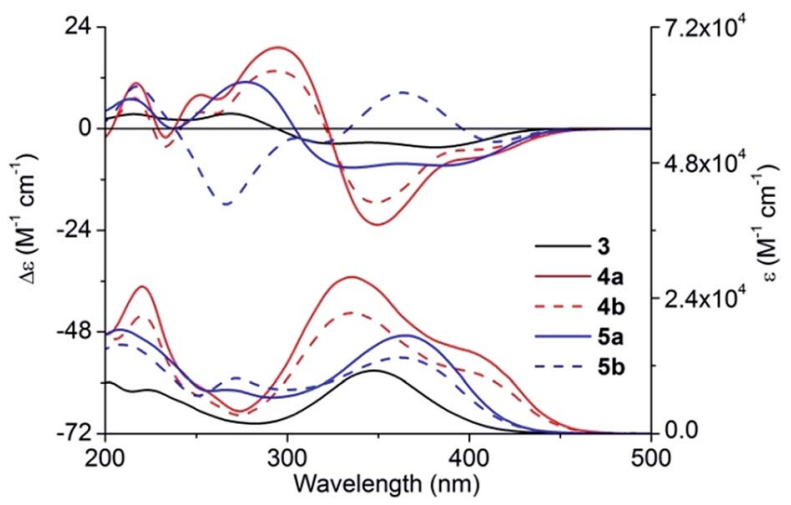

Fig. 2 Experimental ECD and UV-vis absorption spectra of 3, 4a/4b, and $5 a / 5 b$ in methanol.

increased significantly. However, the cyclization decreased the absorption intensity and a new peak was formed at about $270 \mathrm{~nm}$, which corresponded to the $n \rightarrow \pi^{*}$ electronic transition of 2-oxazolidone moiety.

In ECD spectra, compound 3 showed two negative Cotton effects (CEs) in the wavelength range between 300 and $450 \mathrm{~nm}$, and two positive CEs from 200 to $300 \mathrm{~nm}$. As expected, $4 a$ and 4b exhibited quite similar ECD curves, which were substantially different from that of 3 . Two negative CEs of equal intensity above $300 \mathrm{~nm}$ transformed into one intense negative CE and a very weak negative $\mathrm{CE}$ of $\mathbf{4 a} / \mathbf{4 b}$. Compound $5 \mathbf{a}$ showed a similar ECD pattern as $\mathbf{3}$ with part of CEs being red-shifted or blue-shifted about $10 \mathrm{~nm}$. However, ECD spectrum of $\mathbf{5 b}$ possessed a positive $\mathrm{CE}$ at $363 \mathrm{~nm}$ and a negative $\mathrm{CE}$ at $266 \mathrm{~nm}$, where all the other compounds showed CEs of opposite signs.

\section{Structural elucidation}

Quantum chemical calculation parameters might greatly influence calculation results; consequently, ECD calculation of $\mathbf{3}$ was first carried out with caution using various functionals and basis sets. ${ }^{16}$ In total, 28 conformers of $(S)-3$ were taken into account for the theoretical simulation (for main conformers, see Fig. S1, ESI $\dagger$ ). All the theoretical ECD spectra of $(S)-3$ possessed a similar tendency as the experimental ECD curve. Amongst all, ECD prediction at the Cam-B3LYP/6-31 + G(d,p) level using the B3LYP/6-31G(d) geometries offered the optimal fit of CE positions and relative strengths after a red shift of $20 \mathrm{~nm}$ (Fig. 3).

Chiral centres of $\mathbf{4 a}$ and $\mathbf{4 b}$ were not involved during the cyclization step; accordingly, their absolute configurations could be inferred from $\mathbf{5 a}$ and $\mathbf{5 b}$. Unlike ECD spectra of $\mathbf{4 a}$ and $\mathbf{4 b}$, the remarkable difference between ECD spectra of $\mathbf{5 a}$ and $\mathbf{5 b}$ facilitated their absolute configuration assignment.

Adopting the above-mentioned calculation method, theoretical ECD spectra of $\left(2 S, 5^{\prime} R\right)-5$ and $\left(2 S, 5^{\prime} S\right)-5$ were obtained and compared with experimental ECD data of $\mathbf{5 a}$ and $\mathbf{5 b}$ (Fig. 4 and 5; for main conformers, see Fig. S2 and S3†). Thus, their absolute configurations were assigned by comparison of theoretical and experimental ECD spectra. Albeit, it could be anticipated that a better match could be achieved by selecting

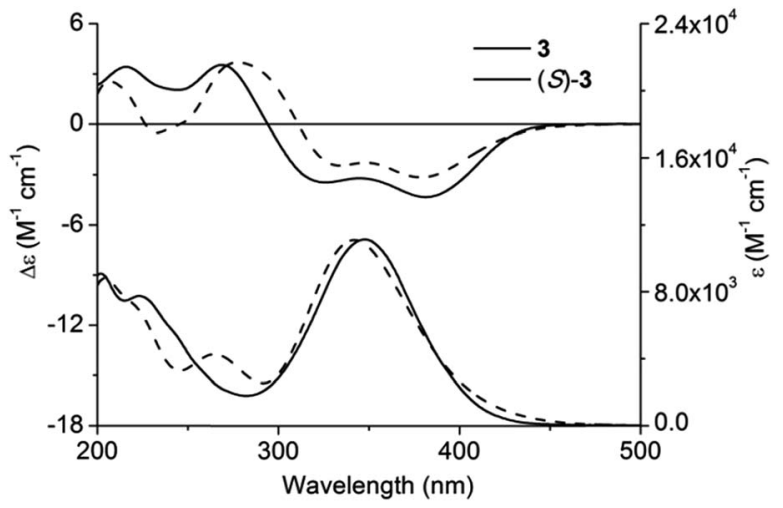

Fig. 3 Experimental and calculated ECD and UV-vis absorption spectra of (S)-3 and 3 in methanol.

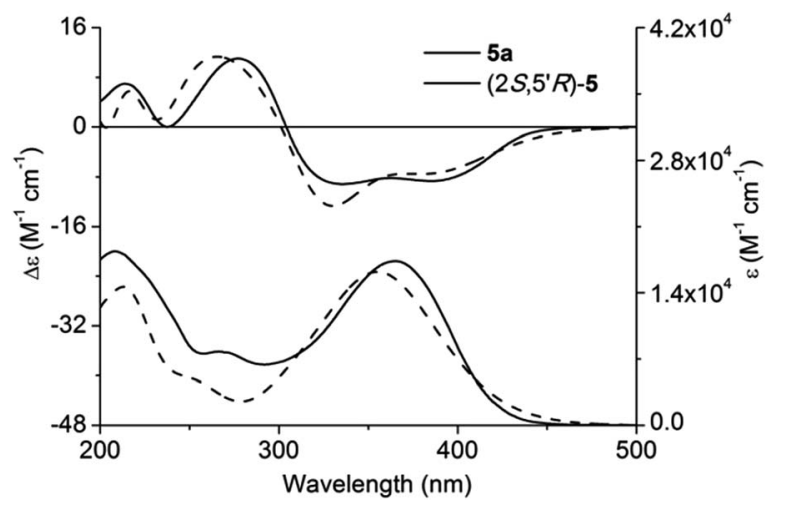

Fig. 4 Experimental and calculated ECD and UV-vis absorption spectra of $\left(2 S, 5^{\prime} R\right)-5$ and $5 a$ in methanol.

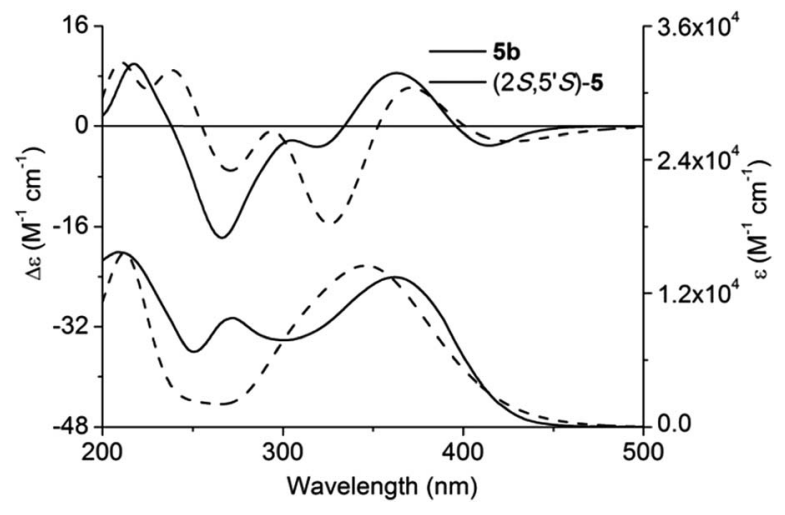

Fig. 5 Experimental and calculated ECD and UV-vis absorption spectra of $\left(2 S, 5^{\prime} S\right)-5$ and $5 b$ in methanol.

suitable functional and basis set conformations. It is clear that the absolute configuration of $\mathbf{5 a}$ is assigned as $\left(2 S, 5^{\prime} R\right)$, and that of $\mathbf{5 b}$ is $\left(2 S, 5^{\prime} S\right)$.

\section{HPLC analysis of diastereomers}

Specificity. Derivatization of racemic 1 with 3 yielded diastereomers $\mathbf{4 a}$ and $\mathbf{4 b}$, which could be resolved with a common 


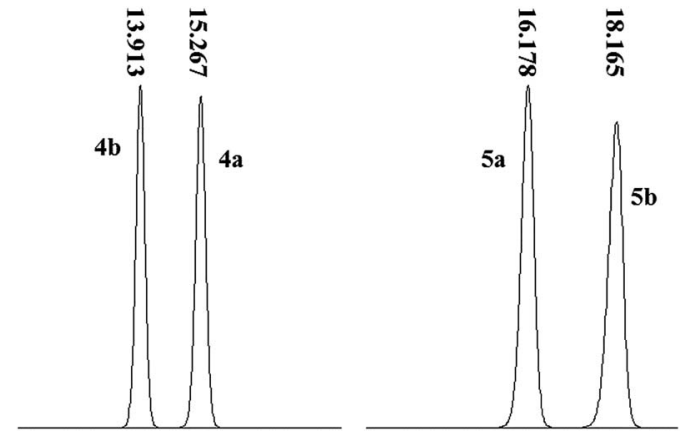

Fig. 6 RPLC profiles of $4 a / 4 b$ and $5 a / 5 b$

C18 stationary phase using RPLC with clear baseline resolution. The use of acetonitrile-water $(50: 50)$ as a mobile phase allowed the most satisfactory separation of $\mathbf{4 a}$ and $\mathbf{4 b}$ with a maximum peak resolution with retention times of $15.27 \mathrm{~min}$ and 13.91 min, respectively (Fig. 6). Moreover, the equivalent peak areas of $\mathbf{4 a}$ and $\mathbf{4 b}$ demonstrated that the chirality of $\mathbf{1}$ exerted no effect on its chemical reactivity with 3 , indicating that the optical purity of $\mathbf{1}$ was preserved after the conversion to $\mathbf{4 a} / \mathbf{4 b}$. Moreover, the elution sequence changed as $5 \mathrm{a}$ (16.178 $\mathrm{min}$ ) followed by $\mathbf{5 b}(18.165 \mathrm{~min})$ after cyclization using a mobile phase of methanol-water (55:45). The optimal absorption signals in terms of signal-to-noise ratio and sensitivity were obtained at $336 \mathrm{~nm}$.

Linearity, relative response factor (RRF), accuracy, limit of detection (LOD) and limit of quantitation (LOQ). The linearity was evaluated by measuring the area response for $\mathbf{4 a} / \mathbf{4} \mathbf{b}$ over the range of $1000-1.9 \mu \mathrm{g} \mathrm{mL}{ }^{-1}$. It is worth noting that plotting the standard curve necessitates more than $99 \%$ purity of the standard samples. Ten concentrations $(n=10)$ were prepared within the range and injected in triplicate. The mean area $(n=3)$ calculated was plotted against the concentration. Linear regression analysis was performed with a correlation coefficient

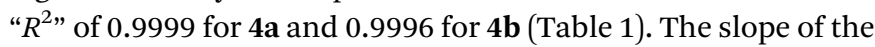

Table 1 Method validation data for $4 a / 4 b$

\begin{tabular}{|c|c|c|c|c|c|c|}
\hline Validation parameter & \multicolumn{3}{|l|}{$4 a$} & \multicolumn{3}{|l|}{ 4b } \\
\hline \multicolumn{7}{|l|}{ LOD, LOQ } \\
\hline $\operatorname{LOD}\left(\mu \mathrm{g} \mathrm{mL}^{-1}\right)$ & \multicolumn{3}{|l|}{0.001} & \multicolumn{3}{|c|}{0.001} \\
\hline LOQ $\left(\mu \mathrm{g} \mathrm{mL}{ }^{-1}\right)$ & \multicolumn{3}{|l|}{0.003} & \multicolumn{3}{|c|}{0.003} \\
\hline \multicolumn{7}{|l|}{ Linearity } \\
\hline Calibration range $\left(\mu \mathrm{g} \mathrm{mL} \mathrm{m}^{-1}\right)$ & \multicolumn{3}{|c|}{$1000-1.9$} & \multicolumn{3}{|c|}{$1000-1.9$} \\
\hline Calibration points & \multicolumn{3}{|l|}{10} & \multicolumn{3}{|c|}{10} \\
\hline Regression equations & \multicolumn{3}{|c|}{$\begin{array}{l}A=0.0434 C+ \\
0.00323\end{array}$} & \multicolumn{3}{|c|}{$\begin{array}{l}A=0.0361 C+ \\
0.0012\end{array}$} \\
\hline Coefficient of determination $\left(R^{2}\right)$ & \multicolumn{3}{|c|}{0.9999} & \multicolumn{3}{|c|}{0.9996} \\
\hline Relative response factor (RRF) & \multicolumn{3}{|l|}{1.202} & \multicolumn{3}{|c|}{1.000} \\
\hline \multicolumn{7}{|l|}{ Accuracy } \\
\hline Recovered $\left(\mu \mathrm{g} \mathrm{mL}^{-1}\right)$ & 600 & 500 & 400 & 600 & 500 & 400 \\
\hline \% Recovery & 101.2 & 98.5 & 99.8 & 99.6 & 98.2 & 100.5 \\
\hline$\% \operatorname{RSD}(n=3)$ & 0.78 & 0.45 & 0.88 & 0.78 & 0.76 & 0.45 \\
\hline
\end{tabular}

calibration curve for $\mathbf{4 b}$ was 0.832 times the slope value of $\mathbf{4 a}$, indicating that the response of $\mathbf{4 a}$ was about 1.202 times higher than $4 \mathbf{b}$. Hence, the RRF of $\mathbf{4 a}$ was 1.202 with respect to $\mathbf{4 b}$.

The accuracy of the method was validated through recovery experiments by spiking known amounts of $\mathbf{4 a}$ and $\mathbf{4 b}$ at concentrations of 300,400 and $500 \mu \mathrm{g} \mathrm{mL}{ }^{-1}$. Each preparation was analysed in triplicate $(n=3)$ and percent recovery was calculated. The recovery was found to be between $98.5 \%$ and $101.2 \%$ with the RSD $(n=9)$ less than $0.88 \%$ (Table 1$)$. The LOD and LOQ for $\mathbf{4 a} / \mathbf{4} \mathbf{b}$ were determined by the signal-to-noise ratio $(\mathrm{S} / \mathrm{N})$ method. The LOD and LOQ obtained for $\mathbf{4 a} / \mathbf{4 b}$ were $0.001 \mu \mathrm{g} \mathrm{mL}^{-1}$ and $0.003 \mu \mathrm{g} \mathrm{mL}^{-1}$, respectively, which is more sensitive than the GC method (LOD is $0.05 \mu \mathrm{g} \mathrm{mL}^{-1}$ ). ${ }^{17}$

Linearity, relative response factor, accuracy, LOD and LOQ of $\mathbf{5 a} / \mathbf{5 b}$. Using the same method, standard curves of $\mathbf{5 a}$ and $\mathbf{5 b}$ were obtained by preparing ten different concentration levels ranging from 1000 to $1.9 \mu \mathrm{g} \mathrm{mL}^{-1}$ (Fig. 7). Seven sample injection analyses from 0 to $8 \mathrm{~h}$, operated to measure the peak areas, reflected a fine robustness with $0.81 \%$ and $0.34 \%$ RSD corresponding to $\mathbf{5 a}$ and $\mathbf{5 b}$, respectively. The precision of the method was measured by injecting $10 \mu \mathrm{L}$ of $5 \mathbf{a}$ and $5 \mathbf{b}$ at a concentration of $250 \mu \mathrm{g} \mathrm{mL} \mathrm{m}^{-1}$ for six times to calculate the peak areas. The RSD of the peak areas also showed a fine result of $0.74 \%$ and $0.39 \%$ for $\mathbf{5 a}$ and $\mathbf{5 b}$, respectively.

\section{Application of this method}

It is demonstrated that both $\mathbf{4 a / 4 b}$ and $\mathbf{5 a} / \mathbf{5 b}$ could be used for the enantiopurity assessment of chiral 1 . However, for the user's convenience, $\mathbf{4 a}$ and $\mathbf{4 b}$ were easier to obtain and thus selected for optical purity analysis. The external standard method could be adopted to determine the accurate concentrations of $\mathbf{4 a}$ and 4b and the optical purity could then be calculated according to their ratio. In addition to the external standard method, a peak area normalization method with a correction factor is a feasible way to detect the exact absolute optical purity of chiral 1 without the use of standard samples. It means that the absolute optical purity of $\mathbf{1}$ could be quantitatively determined by the peak area ratios of two diastereomers, which clearly surpasses the optical rotation method in accuracy.

Four commercially available samples were then assessed for their enantiomeric excess using both the external standard

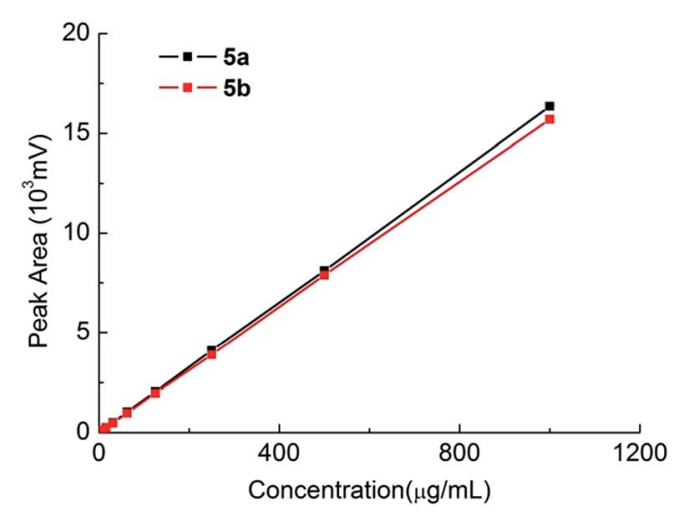

Fig. 7 Standard curves of $5 \mathrm{a}$ and $5 \mathrm{~b}$. 
Table 2 Comparative assessment of ee's of 1

\begin{tabular}{llll}
\hline & & \multicolumn{2}{l}{ Calc. ee\% } \\
\cline { 3 - 4 } & {$[\alpha]_{\mathrm{D}}^{25}$} & Method A $^{a}$ & Method B $^{b}$ \\
\hline Sample 1 & -9.7 & $96.89(R)$ & $96.92(R)$ \\
Sample 2 & +9.9 & $98.3(S)$ & $98.28(S)$ \\
Sample 3 & +6.1 & $87.89(S)$ & $87.87(S)$ \\
Sample 4 & 0 & 0 & 0
\end{tabular}
${ }^{a}$ External standard method. ${ }^{b}$ Peak area normalization method with
a correction factor.

method and the peak area normalization method. The samples were first reacted with 3 to provide the reaction mixture, which was analysed after a simple sample treatment.

As listed in Table 2, both analytical methods provided extremely close ee values. Therefore, in a typical routine determination without requirement of system suitability evaluation, the peak area normalization method with a correction factor is sufficient to provide reliable results without preparing standard curves.

\section{Experimental section}

\section{Reagents and apparatus}

Commercially available reagents were used without further purification. Reactions were monitored by thin-layer chromatography (TLC) using silica gel precoated glass plates visualized with UV light. Flash chromatography columns were packed with 300-400 mesh silica gel. Gradient flash chromatography was conducted with a continuous gradient from petroleum ether (PE) to ethyl acetate (EA), listed as volume/volume ratios. ${ }^{1} \mathrm{H}$ and ${ }^{13} \mathrm{C}$ NMR data were recorded using the Varian Mercury (500 $\mathrm{MHz}$ ) spectrometer with TMS as an internal standard. ESIHRMS data were collected on the Thermo Exactive plus Orbitrap mass spectrometer. Melting points were measured on the Yanaco MP-J3 microscope melting point apparatus. RPLC analysis was carried out using the Shimadzu LC-20A HPLC instrument (Kyoto, Japan) equipped with a UV/VIS detector (SPD-20A) and an auto sampler (SIL-20A). The Shimadzu LC Solution software was used for data acquisition and system suitability calculations. Separation was performed on the Ultimate ${ }^{\circledR}$ XB-C18 column $(5 \mu \mathrm{m}, 4.6 \times 250 \mathrm{~mm})$. Optical rotations were measured on the SGW-5 automatic polarimeter (INESA Inc., Shanghai) in acetonitrile at D line $(589.3 \mathrm{~nm})$ at room temperature (r.t.). ECD spectra were recorded on the Jasco J-815 spectrometer (Tokyo, Japan) in methanol.

\section{Synthesis}

Methyl (5-fluoro-2,4-dinitrophenyl)-(S)-prolinate (3). To a magnetically stirred solution of 1,5-difluoro-2,4dinitrobenzene (2) $(2.1 \mathrm{~g}, 10.0 \mathrm{mmol})$ and $N, N$-diisopropylethylamine (DIPEA) $(3.84 \mathrm{~mL}, 22.0 \mathrm{mmol})$ in tetrahydrofuran (THF), methyl $(S)$-prolinate hydrochloride $(10.0 \mathrm{mmol}, 1.71 \mathrm{~g}$ ) was slowly added. The solution was stirred at room temperature for $5 \mathrm{~h}$ and the progress was monitored by TLC. The solvent was evaporated under reduced pressure, and distilled water was added to precipitate the target compound. The residue was then collected by filtration and washed with distilled water to obtain 3 as a yellow solid $(3.05 \mathrm{~g})$ in a yield of $97.4 \%$.

m.p.: $72-73{ }^{\circ} \mathrm{C} .{ }^{1} \mathrm{H}$ NMR $\left(400 \mathrm{MHz}, \mathrm{CDCl}_{3}\right) \delta(\mathrm{ppm}): 8.61(\mathrm{~d}, J$ $=8.0 \mathrm{~Hz}, 1 \mathrm{H}), 6.56(\mathrm{~d}, J=13.6 \mathrm{~Hz}, 1 \mathrm{H}), 4.47(\mathrm{t}, J=6.8 \mathrm{~Hz}, 1 \mathrm{H})$, $3.76(\mathrm{~s}, 3 \mathrm{H}), 3.52-3.62(\mathrm{~m}, 1 \mathrm{H}), 3.30-3.37(\mathrm{~m}, 1 \mathrm{H}), 2.46-2.56(\mathrm{~m}$, 1H), 2.10-2.22 (m, 2H), 1.96-2.07 (m, 1H). ${ }^{13} \mathrm{C}$ NMR (125 MHz, $\left.\mathrm{CDCl}_{3}\right) \delta(\mathrm{ppm}): 171.3,159.1,156.9,146.2(\mathrm{~d}, J=12.1 \mathrm{~Hz}), 133.1$, 126.8, 104.5 (d, $J=26.9 \mathrm{~Hz}$ ), 62.8, 53.3, 52.5, 31.2, 24.7 (see Fig. S4 $\dagger$ ). ESI-MS calcd for $\mathrm{C}_{12} \mathrm{H}_{13} \mathrm{~N}_{3} \mathrm{O}_{6} \mathrm{~F}[\mathrm{M}+\mathrm{H}]^{+}$314.0783, found 314.0766 (see Fig. $\mathrm{S} 5 \dagger) .[\alpha]_{\mathrm{D}}^{25}=-644.4\left(c=0.5, \mathrm{CH}_{3} \mathrm{CN}\right)$. $\mathrm{UV}\left(\mathrm{CH}_{3} \mathrm{OH}\right) \lambda_{\max }(\log \varepsilon): 348.0$ (4.05), 223.5 (3.89) nm; ECD $\left(\mathrm{CH}_{3} \mathrm{OH}\right) \lambda_{\max }(\Delta \varepsilon): 381.5(-4.34), 345.0(-3.21), 325.0(-3.46)$, $269.0(+3.53), 244.5(+2.04), 216.0(+3.42) \mathrm{nm}$.

Methyl (5-(((R)-1-hydroxybutan-2-yl)amino)-2,4-dinitro-phenyl)(S)-prolinate (4a). Compound 3 (390 mg, $1.25 \mathrm{mmol})$, DIPEA $(436 \mu \mathrm{L}, 2.5 \mathrm{mmol})$ and $(R)-\mathbf{1}(225 \mathrm{mg}, 2.5 \mathrm{mmol})$ were dissolved in anhydrous THF under Ar and the reaction was carried out at $80^{\circ} \mathrm{C}$. The progress of the reaction was monitored by TLC (PE-EA $3: 1$ ). Then the solvent was evaporated under reduced pressure, and the residue was washed with distilled water and dried in a vacuum drying oven to obtain 4 a as a yellow solid (467 $\mathrm{mg}$ ) in a yield of 97.6\%, which was used without further purification.

m.p.: 57-58 ${ }^{\circ} \mathrm{C} .{ }^{1} \mathrm{H}$ NMR $\left(400 \mathrm{MHz}, \mathrm{CDCl}_{3}\right) \delta(\mathrm{ppm}): 8.78(\mathrm{~s}$, $1 \mathrm{H}), 8.32(\mathrm{~d}, J=7.6 \mathrm{~Hz}, 1 \mathrm{H}), 5.92(\mathrm{~s}, 1 \mathrm{H}), 4.40(\mathrm{t}, J=6.8 \mathrm{~Hz}, 1 \mathrm{H})$, 3.75 (s, 3H), 3.66-3.71 (m, 2H), 3.56-3.64 (m, 1H), 3.44-3.54 (m, $1 \mathrm{H}), 3.23-3.30(\mathrm{~m}, 1 \mathrm{H}), 2.42-2.51(\mathrm{~m}, 1 \mathrm{H}), 2.09-2.22(\mathrm{~m}, 2 \mathrm{H})$, 1.79-2.03 (m, 3H), 1.59-1.72 (m, 1H), $1.06(\mathrm{t}, J=7.6 \mathrm{~Hz}, 3 \mathrm{H}) ;{ }^{13} \mathrm{C}$ NMR (125 MHz, $\left.\mathrm{CDCl}_{3}\right) \delta$ (ppm): 173.1, 147.7, 146.6, 129.5, 129.0, 123.7, 95.8, 64.2, 63.4, 57.0, 53.2, 52.4, 30.95, 25.1, 24.8, 10.9 (see Fig. S6†). ESI-MS calcd for $\mathrm{C}_{16} \mathrm{H}_{23} \mathrm{~N}_{4} \mathrm{O}_{7} \mathrm{~F}[\mathrm{M}+\mathrm{H}]^{+}$ 383.1561, found 383.1545 (see Fig. $\mathrm{S} 7 \dagger$ ). $[\alpha]_{\mathrm{D}}^{25}=-918.2(c=0.2$, $\left.\mathrm{CH}_{3} \mathrm{CN}\right)$. UV $\left(\mathrm{CH}_{3} \mathrm{OH}\right) \lambda_{\max }(\log \varepsilon): 402.0$ (4.16), 335.5 (4.44), $220.5(4.42) \mathrm{nm} ; \mathrm{ECD}\left(\mathrm{CH}_{3} \mathrm{OH}\right) \lambda_{\max }(\Delta \varepsilon): 410.0(-6.35), 392.0$ (-7.48), 349.5 (-22.66), 295.0 (+19.17), 261.5 (+6.95), 252.5 (+7.96), $233.5(-1.99), 217.0(+10.73) \mathrm{nm}$.

Methyl (5-(((S)-1-hydroxybutan-2-yl)amino)-2,4-dinitro-phenyl)$(S)$-prolinate (4b). $(S)$-1 was treated as described above to obtain $\mathbf{4 b}$ in a yield of $96.5 \%$.

m.p.: 55-56 ${ }^{\circ} \mathrm{C} .{ }^{1} \mathrm{H}$ NMR $\left(400 \mathrm{MHz}, \mathrm{CDCl}_{3}\right) \delta(\mathrm{ppm}): 8.79(\mathrm{~s}$, $1 \mathrm{H}), 8.39(\mathrm{~d}, J=7.6 \mathrm{~Hz}, 1 \mathrm{H}), 5.97(\mathrm{~s}, 1 \mathrm{H}), 4.42(\mathrm{t}, J=6.8 \mathrm{~Hz}, 1 \mathrm{H})$, 3.75-3.87 (m, 2H), $3.73(\mathrm{~s}, 3 \mathrm{H}), 3.57-3.65(\mathrm{~m}, 1 \mathrm{H}), 3.47-3.56(\mathrm{~m}$, $1 \mathrm{H}), 3.24-3.31(\mathrm{~m}, 1 \mathrm{H}), 2.42-2.53(\mathrm{~m}, 1 \mathrm{H}), 2.08-2.19(\mathrm{~m}, 2 \mathrm{H})$, 1.87-2.01 (m, 1H), 1.69-1.82 (m, 2H), 1.56-1.68 (m, 1H), $1.00(\mathrm{t}, J$ $=7.2 \mathrm{~Hz}, 3 \mathrm{H}) .{ }^{13} \mathrm{C} \mathrm{NMR}\left(125 \mathrm{MHz}, \mathrm{CDCl}_{3}\right) \delta(\mathrm{ppm}): 172.7,147.9$, 146.8, 129.5, 128.9, 123.6, 95.8, 64.3, 63.0, 56.8, 53.0, 52.6, 31.1, 25.1, 24.5, 10.6 (see Fig. S8†). ESI-MS calcd for $\mathrm{C}_{16} \mathrm{H}_{23} \mathrm{~N}_{4} \mathrm{O}_{7} \mathrm{~F}[\mathrm{M}$ $+\mathrm{H}]^{+} 383.1561$, found 383.1540 (see Fig. S9 $\dagger$ ). $[\alpha]_{\mathrm{D}}^{25}=-668.8(c$ $\left.=0.4, \mathrm{CH}_{3} \mathrm{CN}\right)$. UV $\left(\mathrm{CH}_{3} \mathrm{OH}\right) \lambda_{\max }(\log \varepsilon): 402.0$ (4.03), 335.5 (4.33), 220.5 (4.32) nm; ECD $\left(\mathrm{CH}_{3} \mathrm{OH}\right) \lambda_{\max }(\Delta \varepsilon): 410.0(-4.67)$, 392.0 (-5.17), $348.5(-17.38), 293.5(+13.61), 259.5(+3.52)$, $252.5(+3.86), 233.0(-4.18), 216.0(+7.18) \mathrm{nm}$.

Methyl (5-((R)-4-ethyl-2-oxooxazolidin-3-yl)-2,4-dinitro-phenyl)$(S)$-prolinate (5a). Compound $4 \mathbf{a}(160 \mathrm{mg}, 0.42 \mathrm{mmol})$ and DIPEA (366 $\mu \mathrm{L}, 2.1 \mathrm{mmol}$ ) were dissolved in anhydrous THF and 
bis(trichloromethyl)carbonate $(0.42 \mathrm{mmol}, 125 \mathrm{mg})$ in dichloromethane was then added dropwise to the solution in an ice bath. After removing the ice bath, the resulting mixture was stirred for $1 \mathrm{~h}$ at room temperature and the progress was monitored by RPLC. Then, the reaction was quenched by adding several drops of water slowly and concentrated in vacuo, taken up in water and extracted with dichloromethane. The combined organic extracts were washed with brine, dried over $\mathrm{Na}_{2} \mathrm{SO}_{4}$ and concentrated under reduced pressure. Purification by flash column chromatography (PE-EA $1: 3$ ) afforded 5a as a yellow solid (159 mg) in a yield of $92.9 \%$.

m.p.: $153-154{ }^{\circ} \mathrm{C} .{ }^{1} \mathrm{H}$ NMR $\left(400 \mathrm{MHz}, \mathrm{CDCl}_{3}\right) \delta(\mathrm{ppm}): 8.65$ (s, $1 \mathrm{H}), 6.65(\mathrm{~s}, 1 \mathrm{H}), 4.64-4.73(\mathrm{~m}, 1 \mathrm{H}), 4.52(\mathrm{t}, J=6.8 \mathrm{~Hz}, 1 \mathrm{H}), 4.14-$ $4.22(\mathrm{~m}, 2 \mathrm{H}), 3.75(\mathrm{~s}, 3 \mathrm{H}), 3.51-3.60(\mathrm{~m}, 1 \mathrm{H}), 3.18-3.26(\mathrm{~m}, 1 \mathrm{H})$, 2.45-2.55 (m, 1H), 2.11-2.23 (m, 2H), 1.95-2.06 (m, 1H), 1.51$1.76(\mathrm{~m}, 3 \mathrm{H}), 0.92(\mathrm{t}, J=7.2 \mathrm{~Hz}, 3 \mathrm{H}) .{ }^{13} \mathrm{C} \mathrm{NMR}\left(125 \mathrm{MHz}, \mathrm{CDCl}_{3}\right)$ $\delta$ (ppm): 171.5, 156.9, 144.5, 135.12, 134.8, 133.7, 126.8, 118.8, 68.6, 62.8, 59.4, 53.1, 52.3, 30.8, 25.8, 24.9, 8.6 (see Fig. S10†). ESI-MS calcd for $\mathrm{C}_{17} \mathrm{H}_{21} \mathrm{~N}_{4} \mathrm{O}_{8} \mathrm{~F}[\mathrm{M}+\mathrm{H}]^{+}$409.1354, found 409.1340 (see Fig. S11 $\dagger$ ). $[\alpha]_{\mathrm{D}}^{25}=-588.1\left(c=0.1, \mathrm{CH}_{3} \mathrm{CN}\right)$. UV $\left(\mathrm{CH}_{3} \mathrm{OH}\right) \lambda_{\max }(\log \varepsilon): 365.0$ (4.24), 267.0 (3.89), 208.5 (4.26) nm; $\operatorname{ECD}\left(\mathrm{CH}_{3} \mathrm{OH}\right) \lambda_{\max }(\Delta \varepsilon): 385.5(-8.65), 363.0(-8.20), 335.5$ (-9.14), $277.0(+11.01), 237.5(0), 214.0(+6.97) \mathrm{nm}$.

Methyl (5-((S)-4-ethyl-2-oxooxazolidin-3-yl)-2,4-dinitro-phenyl)$(\boldsymbol{S})$-prolinate (5b). Compound $\mathbf{4 b}$ was treated as described above to obtain $5 \mathbf{b}$ in a yield of $91.3 \%$.

m.p.: $151-152{ }^{\circ} \mathrm{C} .{ }^{1} \mathrm{H}$ NMR $\left(400 \mathrm{MHz}, \mathrm{CDCl}_{3}\right) \delta(\mathrm{ppm}): 8.51(\mathrm{~s}$, $1 \mathrm{H}), 6.65(\mathrm{~s}, 1 \mathrm{H}), 4.65(\mathrm{t}, J=8.0 \mathrm{~Hz}, 1 \mathrm{H}), 4.48(\mathrm{t}, J=6.8 \mathrm{~Hz}, 1 \mathrm{H})$, $4.24-4.32(\mathrm{~m}, 1 \mathrm{H}), 4.18-4.23(\mathrm{~m}, 1 \mathrm{H}), 3.74(\mathrm{~s}, 3 \mathrm{H}), 3.50-3.59(\mathrm{~m}$, $1 \mathrm{H}), 3.28-3.36(\mathrm{~m}, 1 \mathrm{H}), 2.46-2.56(\mathrm{~m}, 1 \mathrm{H}), 2.00-2.23(\mathrm{~m}, 3 \mathrm{H})$, 1.56-1.77 (m, 2H), $0.90(\mathrm{t}, J=7.6 \mathrm{~Hz}, 3 \mathrm{H}) .{ }^{13} \mathrm{C}$ NMR $(125 \mathrm{MHz}$, $\left.\mathrm{CDCl}_{3}\right) \delta(\mathrm{ppm}): 171.8,155.8,144.3,134.7,134.22,133.4,126.6$, 115.0, 68.3, 62.9, 58.6, 53.2, 52.3, 31.0, 25.3, 24.9, 8.7 (see Fig. S12 †). ESI-MS calcd for $\mathrm{C}_{17} \mathrm{H}_{21} \mathrm{~N}_{4} \mathrm{O}_{8} \mathrm{~F}[\mathrm{M}+\mathrm{H}]^{+} 409.1354$, found 409.1355 (see Fig. $\mathrm{S} 13 \dagger)$. $[\alpha]_{\mathrm{D}}^{25}=-153.0\left(c=0.2, \mathrm{CH}_{3} \mathrm{CN}\right.$ ). $\mathrm{UV}\left(\mathrm{CH}_{3} \mathrm{OH}\right) \lambda_{\max }(\log \varepsilon): 362.0$ (4.13), 271.5 (3.99), 208.5 (4.20) nm; ECD $\left(\mathrm{CH}_{3} \mathrm{OH}\right) \lambda_{\max }(\Delta \varepsilon): 414.5(-3.03), 363.0(+8.48)$, 318.5 (-3.23), 305.0 (-2.19), 266.0 (-17.81), $217.5(+9.95) \mathrm{nm}$.

\section{RPLC analysis conditions}

Mobile phases. The mobile phases consisted of methanolwater or acetonitrile-water in the ratio of $50: 50(\mathrm{v} / \mathrm{v})$ or $55: 45(\mathrm{v} / \mathrm{v})$. Mobile phases were filtered through a $0.45 \mu \mathrm{m}$ membrane filter (Millipore, Bedford, USA) and degassed before use. The flow rate was $1.0 \mathrm{~mL} \mathrm{~min}^{-1}$ with UV detection at $336 \mathrm{~nm}$. Each sample was injected three times with an injection volume of $10 \mu \mathrm{L}$.

Preparation of solutions. The standard $1 \mathrm{mg} \mathrm{mL}{ }^{-1}$ stock solution was prepared by dissolving about $5 \mathrm{mg}$ of precisely weighted $\mathbf{4 a / 4 b}$ or $\mathbf{5 a} / \mathbf{5 b}$ in the corresponding amount of methanol. The stock standard solution was successively diluted with methanol into 500, 250, 125, 62.5, 31.25, 15.625, 7.8, 3.9 and $1.9 \mu \mathrm{g} \mathrm{mL}^{-1}$ standard solutions.

Analytical procedure. A dead time of $3 \mathrm{~min}$ was utilized in calculations of retention factor and selectivity. Resolutions were calculated using the peak width at half height. Calibration curves were plotted by linear regression between concentrations of standard solutions versus peak area response. Recovery studies were carried out using different standard solutions of known concentrations and mean recovery values (five replicate runs) were represented as the percentage of calculated values. Inter-day and intra-day stability studies were performed to measure the precision and results were represented in \% RSD. Limit of detection (LOD) and limit of quantification (LOQ) were also evaluated to identify the sensitivity of these reagents for detection and quantification.

Quantum-chemical calculations. Absolute configurations of 3a, 5a and $\mathbf{5 b}$ were assigned by comparison of their calculated and experimental ECD spectra. Conformational analysis and ECD calculations were performed using previously reported protocols. ${ }^{18}$ Specifically, one-hundred lowest electronic transitions were obtained for each conformer using various combinations of hybrid functionals and basis sets including B3LYP/631G(d), B3LYP/6-31 + G(d,p), Cam-B3LYP/6-31G(d), Cam-B3LYP/ 6-31 + G(d,p) approaches built in Gaussian 09 software. $^{19}$ Solvent effects were considered by adopting polarizable continuum model (PCM) for methanol using the dielectric constants of 32.613. The overall ECD spectra were then generated at the bandwidth $\sigma=0.35 \mathrm{eV}$ according to the Boltzmann weighting of each conformer.

\section{Conclusions}

Two pairs of diastereomers were designed and synthesized to assess the absolute enantiopurity of $\mathbf{1}$. Their absolute configurations were assigned unambiguously using the TDDFT calculation of ECD spectra via the ring-locking strategy. The linearity, $\mathrm{RRF}, \mathrm{LOD}, \mathrm{LOQ}$, and recovery rates were obtained for $\mathbf{4 a} / \mathbf{4} \mathbf{b}$ and $\mathbf{5 a} / \mathbf{5 b}$. The method could serve as an alternative approach to detect absolute optical purity of $\mathbf{1}$ by regular RPLC without using chiral stationary phase. Furthermore, it consequently affords a promising prospect for analysis of other chiral amino alcohols.

\section{Conflicts of interest}

There are no conflicts to declare.

\section{Acknowledgements}

This study was financially supported by the CAMS Innovation Fund for Medical Sciences (CIFMS, No. 2016-I2M-3-009) and the Fundamental Research Funds for the Central Institutes (No. 2016ZX350003).

\section{Notes and references}

1 (a) Y. J. Chen, Y. H. Chen, C. G. Feng and G. Q. Lin, Org. Lett., 2014, 16, 3400-3403; (b) V. Jha, N. B. Kondekar and P. Kumar, Org. Lett., 2010, 12, 2762-2765; (c) O. K. Karjalainen and A. M. P. Koskinen, Org. Biomol. Chem., 2012, 10, 4311-4326; (d) A. W. Buesking and J. A. Ellman, Chem. Sci., 2014, 5, 1983-1987. 
2 (a) C. P. Pradeep and S. K. Das, Coord. Chem. Rev., 2013, 257, 1699-1715; (b) M. M. Wanderley, C. Wang, C. D. Wu and W. Lin, J. Am. Chem. Soc., 2012, 134, 9050-9053; (c) N. Caldwell, C. Jamieson, I. Simpson and T. Tuttle, Org. Lett., 2013, 15, 2506-2509.

3 (a) M. P. Chelopo, S. A. Pawar, M. K. Sokhela, T. Govender, H. G. Kruger and G. E. Maguire, Eur. J. Med. Chem., 2013, 66, 407-414; (b) M. Mujahid, R. G. Gonnade, P. Yogeeswari, D. Sriram and M. Muthukrishnan, Bioorg. Med. Chem. Lett., 2013, 23, 1416-1419; (c) A. G. Rossi, D. A. Sawatzky, A. Walker, C. Ward, T. A. Sheldrak, N. A. Riley, A. Caldicott, M. Martinez-Losa, T. R. Walker, R. Duffin, M. Gray, E. Crescenzi, M. C. Martin, H. J. Brady, J. S. Savill, I. Dransfield and C. Haslett, Nat. Med., 2006, 12, 10561064; (d) R. Hajjo, C. M. Grulke, A. Golbraikh, V. Setola, X. P. Huang, B. L. Roth and A. Tropsha, J. Med. Chem., 2010, 53, 7573-7586.

4 A. Zumla, P. Nahid and S. T. Cole, Nat. Rev. Drug Discovery, 2013, 12, 388-404.

5 (a) R. G. Wilkinson, R. G. Shepherd, J. P. Thomas and C. Baughn, J. Am. Chem. Soc., 1961, 83, 2212-2213; (b) B. Blessington and A. Beiraghi, J. Chromatogr. A, 1990, 522, 195-203.

6 (a) J. Tomaszewski and M. M. Rumore, Drug Dev. Ind. Pharm., 1994, 20, 119-139; (b) F. W. Fraunfelder, A. A. Sadun and T. Wood, Expert Opin. Drug Saf., 2006, 5, 615-618.

7 R. G. Wilkinson, M. B. Cantrall and R. G. Shepherd, J. Med. Chem., 1962, 5, 835-845.

8 (a) G. M. Dobrikov, V. Valcheva, M. Stoilova-Disheva, G. Momekov, P. Tzvetkova, A. Chimov and V. Dimitrov, Eur. J. Med. Chem., 2012, 48, 45-56; (b) G. M. Dobrikov, V. Valcheva, Y. Nikolova, I. Ugrinova, E. Pasheva and V. Dimitrov, Eur. J. Med. Chem., 2013, 63, 468-473; (c) Z. Petkova, V. Valcheva, G. Momekov, P. Petrov, V. Dimitrov, I. Doytchinova, G. Stavrakov and M. Stoyanova, Eur. J. Med. Chem., 2014, 81, 150-157.

9 (a) N. W. Fadnavis, M. Sharfuddin and S. K. Vadivel, Tetrahedron: Asymmetry, 1999, 10, 4495-4500; (b) D. W. Armstrong, W. Li and C. D. Chang, Anal. Chem., 1990, 62, 914-923.

10 (a) F. Francalanci, P. Cesti, W. Cabri, D. Bianchi, T. Martinengo and M. Foa, J. Org. Chem., 1987, 52, 50795082; (b) S. K. Mishra, S. R. Chaudhari and N. Suryaprakash, Org. Biomol. Chem., 2014, 12, 495-502.

11 (a) E. Yashima, T. Matsushima and Y. Okamoto, J. Am. Chem. Soc., 1997, 119, 6345-6359; (b) M. M. Wanderley, C. Wang, C. D. Wu and W. Lin, J. Am. Chem. Soc., 2012, 134, 9050-
9053; (c) K. W. Bentley, Y. G. Nam, J. M. Murphy and C. Wolf, J. Am. Chem. Soc., 2013, 135, 18052-18055; (d) C. Wolf and K. W. Bentley, Chem. Soc. Rev., 2013, 42, 54085424; (e) P. Zhang and C. Wolf, Chem. Commun., 2013, 49, 7010-7012; (f) C. Wang, E. Wu, X. Wu, X. Xu, G. Zhang and L. Pu, J. Am. Chem. Soc., 2015, 137, 3747-3750; (g) A. Zeus, R. Ding and C. Wolf, Org. Biomol. Chem., 2016, 14, 19341939.

12 (a) N. Berova, L. D. Bari and G. Pescitelli, Chem. Soc. Rev., 2007, 36, 914-931; (b) X. C. Li, D. Ferreira and Y. Ding, Curr. Org. Chem., 2010, 14, 1678-1697; (c) G. Pescitelli, L. Di Bari and N. Berova, Chem. Soc. Rev., 2014, 43, 52115233.

13 (a) P. Marfey, Carlsberg Res. Commun., 1984, 49, 591-596; (b) K. Fujii, Y. Ikai, T. Mayum, H. Oka, M. Suzuki and K. I. Harada, Anal. Chem., 1997, 69, 3346-3352; (c) K. Harada, K. Fujii, K. Hayashi, M. Suzuki, Y. Ikai and H. Oka, Tetrahedron Lett., 1996, 37, 3001-3004; (d) Y. Hou, M. D. B. Tianero, J. C. Kwan, T. P. Wyche, C. R. Michel, G. A. Ellis, E. Vazquez-Rivera, D. R. Braun, W. E. Rose, E. W. Schmidt and T. S. Bugni, Org. Lett., 2012, 19, 50505053; (e) J. G. Adamson, T. Hoang, A. Crivici and G. A. Lajoie, Anal. Biochem., 1992, 202, 210-214; (f) Y. Nozawa, N. Sakai, K. Arai, Y. Kawasaki and K. Harada, J. Microbiol. Methods, 2007, 70, 306-311; $(g)$ H. Yambe, S. Kitamura, M. Kamio, M. Yamad, S. Matsunaga, N. Fusetani and F. Yamazaki, Proc. Natl. Acad. Sci. U. S. A., 2006, 103, 15370-15374; (h) S. Vijayasarathy, P. Prasad, L. J. Fremlin, R. Ratnayake, A. A. Salim, Z. Khalil and R. J. Capon, J. Nat. Prod., 2016, 79, 421-427.

14 K. K. Ngim, J. Zynger and B. Downey, J. Chromatogr. Sci., 2007, 45, 126-130.

15 (a) R. Bhushan and H. Brückner, Amino Acids, 2004, 27, 231247; (b) R. Bhushan and H. Brückner, J. Chromatogr. B: Anal. Technol. Biomed. Life Sci., 2011, 879, 3148-3161; (c) R. Bhushan and V. Kumar, Biomed. Chromatogr., 2008, 22, 906-911.

16 G. Pescitelli and T. Bruhn, Chirality, 2016, 28, 466-474.

17 I. N. Stan'kov, A. A. Sergeeva and S. N. Tarasov, J. Anal. Chem., 2000, 55, 150-154.

18 (a) L. Li and Y. K. Si, Chirality, 2012, 24, 987-993; (b) L. Li, C. Li, Y. K. Si and D. L. Yin, Chin. Chem. Lett., 2013, 24, 500-502; (c) L. Li, B. B. Yang and Y. K. Si, Chin. Chem. Lett., 2014, 25, 1586-1590.

19 Gaussian 09, Revision C. 01, Gaussian, Inc., Wallingford CT, 2010. 